\title{
Research on the Tactics of Critical Thinking Skills Cultivation in Spoken English Teaching Based on Meta Cognition Theory
}

\author{
Qiu-ping HUANG ${ }^{1, a}$, Rui-yun ZENG ${ }^{2, b}$ \\ ${ }^{1}$ College of Foreign Studies, Guilin University of Electronic Technology, Guilin, Guangxi, China \\ ${ }^{2}$ College of Foreign Studies, Guilin University of Electronic Technology, Guilin, Guangxi, China \\ a354712502@qq.com, b602633037@qq.com
}

Keywords: meta cognition; spoken English teaching; critical thinking skills.

\begin{abstract}
This article mainly explores the tactics of critical thinking skills cultivation in spoken English teaching based on meta cognition theory. It can be divided into three parts. The first part illustrates the correlation between meta cognition and English critical thinking ability; the second part analyzes the reasons for the lack of critical thinking ability in college spoken English Teaching. The third part studies the strategies of cultivating students' critical thinking ability in spoken English teaching based on meta cognitive theory.
\end{abstract}

\section{Introduction}

It has reached a general agreement in the academic field and teaching practice that the major purpose of college English teaching is to cultivate the students' oral communicative competence. But unfortunately, the students' English spoken level can not meet the expected requirements, which is mainly manifested in lacking creative opinions or having nothing to say, let alone in-depth analysis and reasoning on the given topics. To a certain extent, their poor performance can be attributed to the shortage of critical thinking ability. Besides, such deficiency will turn into a bottleneck in the English learning process. In order to break through the problem, the author tries to dig out the reasons why the students lack of critical thinking ability in spoken English. Moreover, the College English teacher is advised to adopt some strategies, based on meta cognitive theory, to arrange some targeted training to help students cultivate critical thinking ability .

\section{The correlation between meta cognition and English critical thinking ability}

Meta cognition originates from cognitive psychology, which plays a significant role in language learning strategy theory. It emphasizes learners' reflection on every aspect of learning process and regulates their learning process with knowledge gained from thinking. American psychologist Flavell $^{[1]}$ illustrated that meta cognitive theory refers to the cognitive activities of self-awareness, self-monitoring and self-adjustment. The theory consists of three parts--meta cognitive knowledge, meta cognitive experience and meta cognitive strategy. Being the premise and foundation, the meta cognitive knowledge is the essential part of the theory. Only after acquiring meta cognitive knowledge can individuals enrich their meta cognitive experience and cultivate meta cognitive strategies in specific activities.

Critical thinking ability originated in the west, and its authoritative interpretation is based on the Facione's ${ }^{[2]}$. He stated that critical thinking is a process of self-regulatory judgement with some certain purposes. The development of critical thinking ability involves cultivation of cognitive skills and emotional intention. The cognitive skills cover interpretation, analysis, evaluation and inference and self-correcting ability; the emotional intention includes the courage of questioning, the character of tenacity and the belief of reasoning etc..

It appears that the association between the meta cognition and the critical thinking ability is inseparable, according to the ability relying on knowledge acquisition and accumulation. In other 
words, it is rather difficult for the individual to develop the ability without being guided by knowledge. Put the theory into teaching practice, we can see teaching activities contain various cognitive processes, and there is no exception for the improvement of college students' spoken English. Recent researches show that meta cognitive plays an essential role in spoken English teaching. The students' English critical thinking ability will be promoted greatly on the condition that they can take the initiative to build related ability of meta cognitive knowledge in English learning, recognize their own critical thinking level clearly and grasp the specific methods of logical thinking ability. In addition, they use the knowledge and method guidance to monitor and regulate their English learning activities, meanwhile arousing their own subjective initiative and leading role. These ways are bound to promote the students' critical thinking ability.

\section{The reasons for the lack of critical thinking ability in college spoken English teaching}

It is generally admitted that language is the tool of thinking. To learn a language is to learn to think in this language. Focusing on our spoken English teaching, we will find the college students' logical thinking ability is rather poor while doing oral presentation. This part analyzes the causes of the problem based on meta cognitive theory from the following three perspective.

\section{The separation of language knowledge and thinking ability}

For a long time, the college spoken English teaching has been the "teacher centered" mode. The teacher teaches language knowledge and the students accept it passively. The teacher excessively focuses on the English language teaching and skills training, neglecting the expansion and extension of knowledge. As a result, the students' knowledge structure is relatively homogeneous. This teaching pattern has been stuck in the area of language training. Too much emphasis on language and ignorance of thinking contributes to an optimistic situation, i.e. the amount of information and knowledge which students acquire in the classroom is very limited. While doing oral presentation, they pay more attention to the correct expression to state their points of view clearly or apply the oral mould, following others blindly. Moreover, they lack of logic thinking and language clarity. They raise their points of view in a less prominent way, lacking of thinking, analysis, judgment and reasoning, seldom making in-depth analysis to solve the problem. Therefore, their point of views lack of a certain depth and breadth, which restricts the cultivation of critical thinking skills. In a word, if students' spoken English learning stays on the level of memorizing the language materials mechanically without critical thinking activity, to a certain extent, it will hinder the improvement of spoken English ability.

\section{The lack of meta cognitive knowledge related to critical thinking ability}

In the field of psychology, meta cognitive knowledge refers to the knowledge which guides the development of ability. As an important part of meta cognition, meta cognitive knowledge includes

individual subject knowledge, task knowledge and strategic knowledge "[3][4], which is helpful for students to identify their own learning objectives and strategies. In a comprehensive study of College spoken English class, the weakness of the students' critical thinking ability is largely due to the lack of the above-mentioned meta cognitive knowledge.

First of all, the students' individual knowledge structure is relatively homogeneous, let alone the systematic knowledge structure. Students can only use fragmentary knowledge to express their ideas, and their depth of critical thinking going is relatively restricted. Secondly, the students' oral English learning goals are not clear, being unaware of the core position of critical thinking in spoken English class. While selecting spoken English tasks, they usually have a certain utility and lay particular stress on the acquisition of language skills. That is why many students can only cope with daily oral communication. Once being really involved in a particular topic which demands reasoning, they often have logical confusion and inanity. In addition, as the critical thinking is a relatively unfamiliar task, although the students received oral English strategies training in the 
process of English learning, they know very little about related knowledge of strategy. As a result, they feel difficult to monitor and adjust their learning process.

\section{Insufficient training in meta cognitive strategies related to critical thinking ability}

Strategy is the concrete embodiment of meta cognition. Meta cognitive strategy mainly involves planning, monitoring and adjusting strategies. In college spoken English class, meta cognitive strategies refer to students' plans for oral tasks, monitoring of oral English learning process and evaluation of learning effects before finishing the tasks. A research shows that meta cognitive strategy training plays a significant role in improving students' spoken English ability.

But in real class, meta cognitive strategy training is obviously insufficient. The teacher still follows the traditional spoken English teaching methodology and design some simple routine topics which fail to guide the students to carry on their critical thinking effectively. Besides, it causes students to do a few thinking and questioning in class and act as passive participants all the time. On the other hand, the majority of students' learning goals are not clear, rarely reflecting on their learning methods appropriate or not. In addition, they also do not know how to adjust their learning strategy according to the difficulty degree of the tasks. They learn English by imitating the text structure and format mechanically without independent thinking and reflection on the specific problems, so their language output also stays at a lower level.

\section{The strategies of cultivating students' critical thinking ability in spoken English teaching based on meta cognitive theory}

The core of the ability of critical thinking is to think consciously and to make a rational judgement on the problem. In college spoken English class, the teacher should combine the meta cognitive knowledge with specific teaching activities effectively, then help the students experience the meta cognitive knowledge in specific activities. By using meta cognitive strategies, the teacher will guide the students learning activities so as to achieve critical thinking capacity. In details, we can try from the following aspects.

\section{To guide students to improve their knowledge structure based on the curriculum content}

In the traditional spoken English class, there are usually some communication and interaction activities between teachers and students, but most of them are limited to light conversations and communication. The reason partially lies in the lack of personal knowledge structure of students. From this point of view, the teacher should focus on spoken English teaching tasks, consciously guiding students to do some extra-curricular reading and accumulate or thoroughly acquainted with some knowledge about humanities, history and sociology. In a result, the students are likely to burst out the spark of thought in speaking. The students use meta cognitive knowledge to do planning, inspection, adjustment and evaluation for critical thinking skills again and again, showing their own initiative leading roles. In a word, this is a subtle way to strengthen the students' thinking ability by carrying out the content based teaching, combining the ability training with teaching activities via meta cognitive knowledge and uniting the knowledge and language learning together to improve students' ability of analyzing and solving problems.

\section{To innovate teaching mode to help students build knowledge of critical thinking tasks}

The main reason for students' critical thinking ability being weak is the lack of corresponding teaching circumstances. "Our teaching activities are not cultivating students' ability to think at a high level, but to strengthen the students' ability to think at a lower level" ${ }^{15]}$. In recent years, although the college spoken English textbooks have undergone much reform, being added some critical thinking topics, the cultivation of critical thinking ability has not been given much attention 
in the spoken English class. Therefore, in order to help students build up meta cognitive knowledge of critical thinking tasks, we need to innovate the model and take the cultivation of critical thinking ability as an important teaching goal.

First of all, the teacher should not act as a one-way knowledge role in spoken English class and need to adopt various teaching methods, encouraging students to raise questions. Taking a Socratic teaching method as an example, this is a very good guide method with the design of a series of issues which attract the students to probe the oral topics deeply and guide students thinking. Teachers can also design some open-ended questions to cultivate students' ability of thinking habits and dealing with problems from multiply perspectives. Secondly, teachers can design some challenging oral tasks carefully, such as keynote speech, debate or problem-solving activities, so as to stimulate students' critical thinking ability and train students' logical thinking and comprehensive analysis.

\section{To strengthen self-study and guide students to carry out critical thinking strategy training}

Meta cognitive strategy emphasizes the cognition and adjustment of learning process, and its core is planning, monitoring and adjusting which requires learners' higher autonomy. Autonomous learning is based on meta cognitive monitoring. Students find inadequacy in their autonomous learning process, then use meta cognitive strategies to adjust learning progress in order to complete learning tasks effectively.

In specific oral English teaching activities, due to the restriction of large-size class teaching mode, students' spoken ability training is far from enough inside the classroom. It is accepted that the self-learning in spoken English is an efficient way. Teachers should improve their meta cognitive awareness on the basis of teaching meta cognitive knowledge, train them to monitor and adjust the process of oral training actively. At the same time, Teachers should guide students to make full use of the advantages of modern educational technology, especially the autonomous learning network platform. By using the rich resources such as audio, video and others, students make plans to learn and absorb the language knowledge and develop thinking skills.

In order to test the students' autonomous learning, teachers may select some comprehensive learning resources and design the topics of critical thinking. By doing the tasks, students learn to take the initiative, using the language knowledge they have learned to induct and refine, then reconstruct their points of view. This is a kind of independent thinking and creative thinking process. While improving their autonomous learning ability, the students' thinking ability is also improved effectively.

To reform the standard and mode of oral evaluation with the purpose of promoting the transformation of cognitive ability to the critical thinking ability

The traditional spoken English tests often focuses on the accuracy and fluency of language output. It doesn't pay much attention to the deeper factors such as logic and creativity of language. Influenced by the superficial evaluation standard, students often overemphasize language skills training in their oral learning activities and ignore the critical thinking ability because it is irrelevant to the exam emphasis. Therefore, in order to cultivate students' ability of critical thinking, the most important thing is to better the assessment system of spoken English.

For the evaluation criteria of the critical thinking ability, some scholars put forward "Both of the cognitive elements and emotional qualities should be given attention to" ${ }^{[6]}$. On the basis of this type of evaluation standard, the teacher should continuously enhance the consciousness of the students' thought and encourage them to break the mental barriers to learn to "justify". This is a process from cognitive awareness to cognitive experience, and then to the cognitive thinking development.

Moreover, teachers should strengthen the intelligent evaluation content, reduce the evaluation weight in formative evaluation mechanism. The evaluations can be varied from debate, speech, portfolio, presentation to project. The different forms will be helpful to inspire students' thinking and creating ability. Those who get awards in all kinds of oral contest should be given extra points 
or other forms of reward. Only in this way will the means motivate students to improve meta cognitive ability in spoken English.

\section{Summary}

This article explains the correlation between meta cognition and English critical thinking ability. Then it analyzes the reasons for the lack of critical thinking ability in college spoken English teaching. Finally it probes the strategies of cultivating students' critical thinking ability in spoken English teaching based on meta cognitive theory, such as to guide students to improve their knowledge structure based on the curriculum content, to innovate teaching mode to help students build knowledge of critical thinking tasks, to strengthen self-study and guide students to carry out critical thinking strategy training, to reform the standard and mode of spoken English evaluation and promote the transformation of cognitive ability to the critical thinking ability. For the viewpoints proposed in this article, the author will try to test them in the future College English teaching practice.

\section{Acknowledgements}

This work is supported by the Foundation project: Guangxi Higher Education Institution Research Project (201203YB079); Guangxi Higher Education Teaching Reform Project (2013JGB152).

\section{References}

[1] Flavell. Meta cognition and congnitive monitoring: A new area of cognitive-developmental inquiry[J]. American Psychologist,1979,(34):906-911

[2] Facione.P.A. Facione,N.CGiancarlo, C. A. California critical thinking disposition Inventory: Inventory Manual[M]. Millbrace, CA: The California Academic Press,2001.

[3] Zhang, J. Zhang, L. Meta cognition, metalinguistic awareness, self-regulation and foreign language teaching. Chinese foreign language education [J], 2008, (2): 56-65

[4] Mohan, B\& G.H. Beckett. A functional approach to research on content-based language learning: Recasts in caused explanation[J].Modern language Journal, 2003,(3)

[5] Q, Wen. Oral English teaching and development of students thinking ability. Foreign language teaching [J], 1999, (2): 1-4

[6] Y, Song. The role of the theory of communication in the oral English teaching to improve the students' ability. Foreign language and foreign language teaching [J], 2012, (5): 34-38 